\title{
Obese Hypogonadal Men Treated with Testosterone Undecanoate Injections up to Five Years Substantially and Progressively Lose Weight
}

\author{
Saad F1,2, Haider A3, Doros $\mathrm{G}^{4}$, Traish A ${ }^{5}$ \\ ${ }^{1}$ Global Medical Affairs Andrology, Bayer Pharma, Berlin, Germany; \\ ${ }^{2}$ Gulf Medical University, Ajman, UAE; \\ 3Private Urology Practice, Bremerhaven, Germany; \\ ${ }^{4}$ Biostatistics Consulting Group, Boston University, Boston, Mass, USA;
}

${ }^{5}$ Department of Biochemistry and Urology, Boston University School of Medicine, Boston, Mass, USA

\begin{abstract}
Introduction
Abdominal adipose tissue suppresses testosterone production by various mechanisms affecting the hypothalamic-pituitarygonadal axis. Hypogonadism leads to further accumulation of fat mass thus creating a vicious circle. This study analysed the effects of restoring testosterone in obese hypogonadal men.

Methods

Cumulative, prospective, registry study of 181 men (mean age: $59.11 \pm 6.06$ years) with testosterone levels below $12.1 \mathrm{nmol} / \mathrm{L}$ and a body mass index (BMI) of $\geq 30 \mathrm{~kg} / \mathrm{m} 2$. All men received parenteral testosterone undecanoate $1000 \mathrm{mg} / 12$ weeks following an initial 6-week interval. 89 men were treated five years, 114 four years, 133 three years, 159 two years, 181 one year. The changing numbers do not reflect drop-out rates but are a result of the design as new patients are added once they have received at least one year of treatment.

Results

At the end of the observation period, mean weight $(\mathrm{kg})$ decreased from $114.71 \pm 11.59$ (minimum 87.0, maximum 139.00 ) to $93.24 \pm 8.49$ ( $\min 80.0 ; \max 115.0)$. This decrease was statistically significant vs baseline $(p<0.0001)$ and each year compared to previous year $(p<0.0001)$. Mean change from baseline was $-16.41 \pm 0.3 \%$. After five years, all men had lost any weight, $99 \%$ had lost $\geq 5 \mathrm{~kg}, 90 \% \geq 10 \mathrm{~kg}, 70 \% \geq 15 \mathrm{~kg}$, and $40 \% \geq 20 \mathrm{~kg}$.

Waist circumference $(\mathrm{cm})$ as a measure of abdominal fat decreased from $111.2 \pm 7.54$ ( $\min 89.00$; $\max 129.00)$ to $100.47 \pm 7.11$ ( $\min 84.00$; $\max 117.00$ ), BMI from $36.72 \pm 3.72$ ( $\min 30.10 ; \max 46.51)$ to $30.22 \pm 2.6(\min 25.66 ; \max 36.71)$.

Fasting glucose decreased from $5.84 \pm 0.84$ to $5.41 \pm 0.12$ $\mathrm{mmol} / \mathrm{L}$, total cholesterol from $7.63 \pm 0.95$ to $4.9 \pm 0.28$, LDL from $4.47 \pm 1.03$ to $2.94 \pm 0.93$, triglycerides from $3.31 \pm 0.56$ to $2.17 \pm 0.13 \mathrm{mmol} / \mathrm{L}$. Systolic blood pressure decreased from $159.17 \pm 15.9$ to $139.08 \pm 10.99 \mathrm{mmHg}$, diastolic blood pressure from $96.5 \pm 11.01$ to $80.39 \pm 7.51 \mathrm{mmHg}$ ( $p<0.0001$ for all).
\end{abstract}

\section{Conclusions}

Normalising testosterone produced loss of weight/ waist circumference and improved metabolic profile. These improvements were progressive over five years.
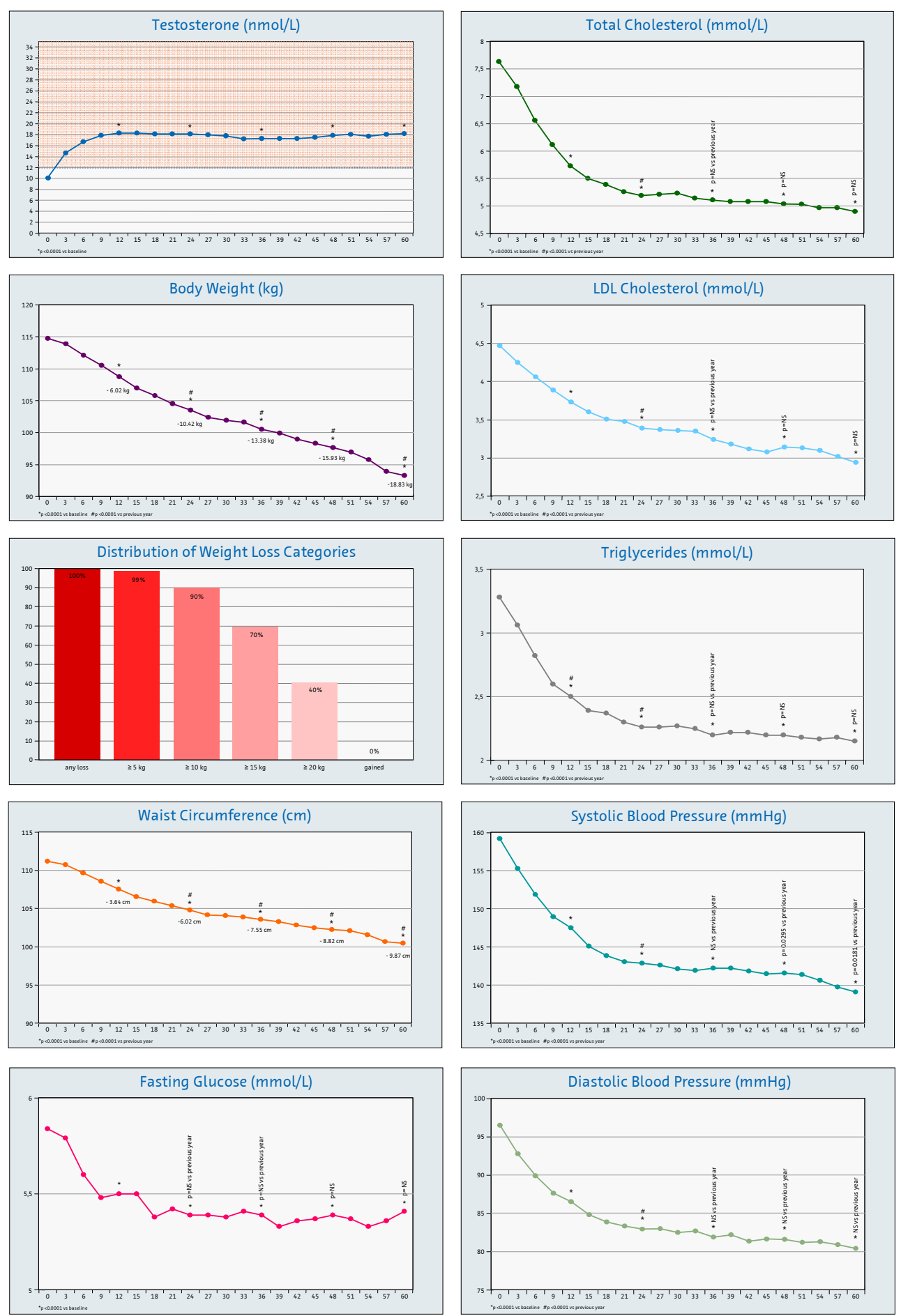